\title{
SIEMPRE FUI BUENA PARA LOS NÚMEROS: POESIA, AFETO E ECONOMIA PARA NURIT KASZTELAN
}

\section{Luciana di Leone*}

\begin{abstract}
Resumo: Nas últimas décadas, boa parte da crítica de arte concentrou os seus esforços de leitura na reflexão sobre o viés relacional das produções contemporâneas, chegando a ser identificado este interesse como sintoma de um "giro afetivo". Isto ocorreu também em parte significativa da produção de poesia, que insistia em encenar um endereçamento, uma vontade de sair de si, uma intenção de envio: ir ao encontro de um Outro, seja o leitor, seja outras linguagens, um encontro que implicaria o poder de afetar e ser afetado. Meu texto se propõe conduzir a discussão em torno dos afetos em direção a uma reflexão econômica (ou melhor, oikonomica). Para isso, a partir da leitura de alguns poemas do livro Lógica de los accidentes, de Nurit Kasztelan (Editorial VOX, 2013), analisaremos a economia de trocas e suas falhas e insuficiências, e como essa troca econômica é inseparável de uma lógica afetiva.
\end{abstract}

Palavras-chave: Poesia contemporânea. Afeto. Economia.

\section{AFETIVIDADE E NÃO-AUTONOMIA}

Nas últimas décadas, ou nos últimos anos, boa parte da crítica de arte e cultural concentrou os seus esforços de leitura na reflexão sobre o viés relacional das produções contemporâneas, chegando a ser identificado este interesse, mas também aquilo que estava se produzindo na arte, como sintoma de um "giro afetivo" (the affective turn, na expressão que tomou conta da academia americana). Isto ocorreu também em parte significativa da crítica de poesia, que começou a dedicar atenção (lendo principalmente a poesia atual, mas também poesia de outras épocas) a alguns elementos que ao longo do século XX foram pouco ou nada analisados por uma perspectiva crítica dominante alicerçada na autonomia da arte. O giro afetivo, ou o interesse numa estética relacional, podemos dizer neste sentido, se apresenta como correlato de um interesse numa poesia não-autônoma, na qual esteja primeiramente em jogo uma dimensão ritual, comunitária, circunstancial, e não a procura de uma forma acabada ou de uma voz própria poética.

Assim, o interesse no endereçamento da poesia, na sua vontade de sair de si, na sua intenção de envio - para utilizar o conceito derridiano -, marcou uma tentativa de sair de uma avaliação do poema como forma final, como resultado de um procedimento levado adiante por um sujeito consciente, e que, na sua forma, veicula uma crítica social, como entenderia Adorno. Diz Derrida (1996, p. 95) ${ }^{1}$, referindo-se ao envio:

\begin{abstract}
Não é originário ou originariamente envio-de (envio de um ente ou de alguma coisa presente que lhe precederia, ainda menos de um sujeito, ou de um objeto por e para um sujeito). Não constitui unidade e não começa consigo mesmo, embora não há nada presente que lhe preceda; não emite mais que remetendo já, não emite mais que a partir do outro, do outro nele sem ele. Tudo começa com o remeter, isto é, não começa.
\end{abstract}

\footnotetext{
* Doutora em Letras pela Universidade Federal Fluminense. Professora Adjunta no Departamento de Ciências da Literatura da Universidade Federal do Rio de Janeiro. E-mail: lulidileone@yahoo.com.ar.

${ }^{1}$ Tradução minha a partir da versão em espanhol.
} 
Em outras palavras, em uma perspectiva não-autônoma, a poesia e a sua crítica passaram a colocar em evidência uma característica que a aquela lhe seria própria (e não circunstancial): ser menos uma obra fechada, ou ter uma identidade, uma ontologia, e ser mais algum tipo de relação, marcada pelo endereçamento, o ir ao encontro de um Outro, um encontro que implicaria o poder de afetar e ser afetado.

Se retornarmos à Ética (1965 [1661-1675]) de Spinoza, na qual geralmente se alicerçam as reflexões contemporâneas sobre os afetos, poderíamos observar que na ideia central segundo a qual um corpo aumenta ou diminui a sua potência de agir a partir das afecções que ele pode experimentar há, em primeiro lugar, uma economia. Pensar os afetos, em Spinoza, é pensar a gestão desses afetos em chave relacional. Isto é sublinhado por Gilles Deleuze quem, na sua retomada de Spinoza, nos aproxima de uma noção de afeto eminentemente relacional. Refere "o estado de um corpo considerado como sofrendo a ação de um outro" (DELEUZE, 1978, s.p.), o que implica em uma mistura de dois corpos, o afetado e o afetante, deixando "imagens ou marcas corporais" (DELEUZE, 2002, p.55), os resíduos do afeto. O homem, enquanto ser consciente, recolheria apenas os efeitos desses encontros, que se dão na forma de paixões: alegria ou tristeza. Neste sentido, o afeto - seja como vestígio de uma afecção, seja como sentimento por ela provocado - é um tipo de marca ou pegada que se subtrai à representação, que não é localizável nem identificável enquanto tal, mas apenas através dos seus vestígios. Esta noção de afeto se afasta de qualquer associação com a expressão de uma interioridade e das definições de sujeito do conhecimento que alicerçaram as interpretações construtivas da arte. Pelo contrário, o afeto se dá como resultado de uma relação, dos efeitos de um corpo sobre outro em variação contínua, de uma mútua modificação.

Mas é significativo que, em Spinoza, as análises dessas mútuas modificações se façam através de uma linguagem próxima da administração, marcada pelas referências a medições e avaliações. Para ele, um corpo é capaz de Paixões e diz, "entendo por Paixões as afecções do corpo pelas quais o poder de agir deste corpo é acrescido ou diminuído, auxiliado ou reduzido" (SPINOZA, 1965, p. 139). Um encontro é "adequado" ou "não adequado", "aumenta" ou "diminui" a potência, e isto pauta relações causais e lógicas, apresentações por axiomas e proposições que permeiam a retórica do texto todo da Ética: se suceder x, consideraremos y, e não z; por isso; assim, segue-se; quanto maior $x$, tanto mais $y$, e assim por diante.

Observemos ainda que, para falar das características da mútua modificação, Spinoza não utiliza as noções de Bem ou Mal, senão o bom e o mau. Em um primeiro sentido, bom seria aquilo que convém à nossa natureza, pois ao se colocar em relação aumenta a nossa potência (por exemplo, um alimento), enquanto que o mau seria aquilo que decompõe a relação do nosso corpo (um veneno). Isto tem a ver com os modos de existência que estarão determinados pela capacidade de organização dos encontros que aumentem a própria potência (bom) e não os que a entreguem ao acaso dos encontros cujos efeitos acabam determinando o comportamento ( $m a u$ ). Certamente, é possível pensar que a tradição moderna, e também Spinoza, valora de forma positiva a "moderação" - utilizando a expressão de Marilena Chaui (2012) - dos encontros, dos afetos, das modificações pela Razão, evitando as determinações extrínsecas ou os 
encontros fortuitos; evitando que esses encontros coloquem o corpo no risco da dissolução dos seus limites claros, enquanto que a reflexão que se aproxima das noções de contágio e contato dariam um valor positivo a uma afetação mútua com aquilo que poderia questionar a própria identidade, como tem apontado entre outros Roberto Esposito em Communitas (2007).

Assim, a questão da avaliação dos afetos me interessa não por uma vontade de dirimir quais encontros são bons ou maus, nem para fazer pesar mais a balança para o lado do acaso ou o da razão, mas pelo impasse que a própria cena expõe. Eles não são causa nem resultado, não são controlados totalmente nem pelo sujeito consciente nem pelo inconsciente, nem pelo contexto histórico nem pelo acidental, eles se subtraem a toda relação causal fixa ou predeterminada. Os afetos só são definíveis na sua circunstancialidade e contingência, sem consistência substancial ou ontológica, eles se apresentam enquanto prática, como uma coreografia na qual os corpos se dispõem, se organizam e moderam, isto é: enquanto uma economia.

\section{AFETIVIDADE E ECONOMIA: QUESTÕES DE PRÁTICA}

Esta possibilidade de pensar a economia enquanto prática é trabalhada por Giorgio Agamben em O reino e a Glória (2007). Ali, Agamben se dedica a percorrer o significado do termo oikonomia (oiko: casa, nomos: lei ou organização) e o seu desenvolvimento no pensamento dos padres da igreja, pelo qual se funda o paradigma trinitário, a sua continuidade no pensamento jurídico e político. Embora não seja o meu interesse estudar em primeira instância a questão teológica, é importante apontar que, para Agamben, é na definição da oikonomia que se jogaria não apenas a genealogia da teologia mas a da própria política, do governo e do poder. Se Carl Smith aponta que, "todos os conceitos decisivos da moderna doutrina do Estado são conceitos teológicos secularizados" (SMITH apud AGAMBEN, 2011, p. 14), Agamben vai postular que a oikonomia, enquanto noção gerencial, essencialmente associada a uma prática e não, como pode resultar comum, a uma racionalidade, a um procedimento cognitivo, ou a uma epistemologia, é a noção que está na base da teologia e seus desdobramentos modernos na ideia de governo e de burocracia. Em Ocidente, para ele, o poder assume a forma de uma oikonomia.

No começo, foi a práxis. No começo, foi a administração da casa, a prática do viver junto, parece se depreender da genealogia levada adiante por Agamben. Diz ele: 'O que une essas relações 'econômicas' (cuja diversidade é sublinhada por Aristóteles [quem as divide em relações 'despóticas', 'paternais' e 'gámicas']) é um paradigma que poderíamos definir como 'gerencial' e não epistêmico" (2011, p. 31). Paradigma que, portanto, se distancia de um pensamento dedutivo para coadunar racionalidade e corporalidade através da práxis. Desse modo, a noção de oikonomia nos permite reconduzir a reflexão sobre as produções humanas e seu governo para a observação da articulação da dicotomia ser e agir, e as dicotomias que a ela se associam: o ser de Deus e a sua atividade; ontologia e práxis; inspiração e construção ${ }^{2}$.

\footnotetext{
${ }^{2}$ Há, segundo Agamben, na relação entre economia e glória, entre governo e reino uma intimidade estruturante da máquina de poder ocidental.
} 
No percurso desta arqueologia, Agamben aponta algumas particularidades do termo oikonomia, entre elas o seu significado retórico que na dupla tradução latina - em dispositio e dispensatio - permite rapidamente aproximar o trabalho de ordenamento do discurso dos momentos onde a linguagem não se deixa conter. A disposição do discurso é, ao mesmo tempo, uma organização e um dispêndio, o que nos permitiria realizar a associação entre as noções de economia e de despesa, relações trabalhadas por Georges Bataille (1933), no que ele mesmo chama de estudo de "economia política", em A parte maldita.

Bataille tenta ali aproximar a arte (além do jogo, e do sacrifício) de uma reflexão econômica já que, para ele, nem a filosofia nem a literatura podem "ser tidas como independentes dessa questão primeira da economia" (BATAILLE, 1975, p. 50). O próprio princípio da despesa, que para Bataille marcaria a poesia, está situado no termo da atividade econômica. "O prazer, quer se trate de arte, de desregramento admitido ou de jogo, é definitivamente reduzido, nas representações intelectuais que estão em curso, a uma concessão, ou seja, a um descanso cujo papel seria subsidiário" (p. 38), diz Bataille na década de trinta, mostrando que as saídas da lógica capitalista e utilitária eram domesticadas a partir da ideia de evasão ou compensação, reduzindo a arte a uma concessão necessária à inutilidade. Bataille, apoiando-se nos textos de Marcel Mauss, observa que nas sociedades primitivas "a troca ainda é tratada como uma perda suntuária dos objetos cedidos: apresenta-se assim, basicamente, como um processo de despesa sobre o qual se desenvolveu um processo de aquisição" (p. 33). Gasto e aquisição, doação e troca, glória e governo, se revelam aqui unidos e não como lógicas totalmente opostas, como se na vontade de aquisição (e capitalização) que hoje impera na sociedade habitasse o princípio da perda.

Com o mesmo intuito de reaproximação entre a economia e aquilo que não se sujeita a um paradigma exclusivamente mercantil e lucrativo, em 1960, o economista François Perroux escreve Economia e sociedade. Coação, troca, dom. Para Perroux, "os estímulos dos atos econômicos podem ser observados em três níveis: o condicionamento, o cálculo e a inspiração" (PERROUX, 1962, p. 97), porém, as sociedades de mercado teriam privilegiado apenas a troca, troca enquanto ato calculado e condicionado, esquecendo a sua dimensão "inspirada". Neste sentido, Perroux denuncia que, por causa da generalização desta perspectiva, toda troca, todo intercâmbio, todo evento econômico, foi reduzido a uma questão de lucro. Enquanto que, observar as trocas a partir da dimensão de doação (aqui incluídas as ideias de inspiração e de despesa) ou inclusive da coação (condicionamento) nos levaria por seu viés mais político e filosófico, nos obrigaria a restituir a problematicidade não dicotômica a um pensamento sobre as artes e sobre a economia. As ideias de doação e gratuidade são geralmente eliminadas das análises econômicas - e circunscritas ao plano da moral - porque, metodologicamente, se "evita que se façam perguntas sobre certa ordem de realidades que perturbariam o quadro ideal que a sociedade de mercado oferece a si mesma", enquanto que "o econômico transborda por todos lados o câmbio mercantil e suas motivações” (PERROUX, 1962, pp. 100-101).

\footnotetext{
${ }^{3}$ Tradução minha a partir da versão em espanhol.
} 


\begin{abstract}
Para mí la literatura no es algo que se elije sino que te sucede. Como enamorarse. Armé toda mi vida en base a los libros. Todo se trataba de cómo conseguir los libros que necesitaba para mi existencia. Ahora soy librera: abrí una librería atípica en mi casa, especializada en poesía y narrativa contemporánea. Cuando generé el emprendimiento, no existían este tipo de proyectos, concentré todas las editoriales independientes en un solo lugar y empecé a tener cada vez más clientes. Ya muchos lo saben, soy licenciada en economía y podría haber elegido otro rumbo. Probé el estado, pero duré cuatro años y renuncié. Renuncié sin saber que iba a hacer, siguiendo una revelación que me dio Clarice Lispector "A la organización no se le opone la desorganización sino una forma nueva". Yo lo único que sabía, es que quería leer.
\end{abstract}

No último vinte de junho, Nurit Kasztelan (bacharel em economia, estudante de Letras, e autora do livro de poemas Lógica de los accidentes, 2013) publica estas palavras no mural do facebook da Librería Mi Casa, a sua livraria. Librería Mi Casa é uma livraria atípica, como diz sua apresentação, que começou a funcionar por volta de 2008, segundo o depoimento, como parte de uma prática anterior, a prática de conseguir, de arrumar, os livros que garantem a existência. A frase pode ser lida com uma certa ambiguidade: não sabemos se o necessário à existência são os livros, ou conseguir os livros - se o necessário para viver são as coisas, ou a sua organização no espaço - como acontece com o Benjamin colecionador, quando está desempacotando a sua biblioteca. Literatura e economia se associam na produção de Nurit Kasztelan, desse modo, não apenas pelo dado biográfico de ter estudado as duas disciplinas, mas por ambas serem modos de existência, modos muito próximos.

Isto é evidente nos poemas que compõem Lógica de los accidentes. O livro se divide em três partes: a primeira chama-se "Interrupción del equilibrio"; a segunda, "El amor era um juego inestable"; a terceira, "Alterar la geometría lineal". Como no título geral, nesses subtítulos, a referência a instâncias de observação e medição aparece como uma tentativa de entender e intervir nas polarizações, que se mostram falidas. Assim, entre o lógico e o acidental, se procura a intersecção: a lógica dos acidentes, ou - como parece se depreender da leitura do livro - os acidentes da lógica. Já, perante a dicotomia equilíbrio/desequilíbrio, opta-se por uma interrupção, como se o livro e o sujeito que nele se encena fossem flagrados no instante em que já não mais há equilíbrio nem racionalidade, e ainda não se deflagrou o caos do desequilíbrio. No amor, identifica-se não a sua previsibilidade nem a sua total imprevisibilidade, mas a combinação do regramento e desregramento, uma combinação de todos os tipos de jogo. Tipos, lembremos, elencados por Caillois (1986) como de agon (de competência e guerra), os jogos de alea (jogos de sorte ou azar), os jogos de mimicry (de simulação e ilusionismo), e os de ilinx (os jogos de vertigem, onde os limites do próprio corpo são abertos por forças centrípetas e centrífugas, por quedas e alçamentos, por tontura). Em todos esses subtítulos é como se, ao mesmo tempo em que se quer medir e organizar o sensível, aparecesse a constatação de que a conta não fecha.

Desse modo, são os paradoxos - um tipo de economia - os que banham os poemas. Diz o poema "Paradojas" (KASZTELAN, 2013, p. 13): 


\author{
El problema no es \\ la falta de aire \\ el problema es el miedo \\ a la falta de aire
}

\begin{abstract}
Busco
en el diccionario hiperventilación:

un exceso de oxígeno

en la sangre. Todo

una cuestión de intensidad.

La paradoja

sigue siendo la misma:

aire más aire igual falta,

una ecuación matemática.
\end{abstract}

aumento de la frecuencia respiratoria,

Desmonta-se a dicotomia e a lógica, através do vínculo espectral - velho conhecido dos poetas e dos psicanalistas - entre a presença e a falta. "El miedo siempre/ que en el futuro falte" (KASZTELAN, 2013, p.12). O medo é o medo da falta, ou mais, o medo da presença da falta, o medo que é a própria presença da falta, que se torna constitutivo da prática poética, de sua economia tensa, de perda, aquisição, e de aquisição de perda. Herda-se a dívida.

Diz em "Variables" (KASZTELAN, 2013, p. 35):

Noventa y nueve más dos

es ciento uno, ¿no?

Dije mirando por la ventanilla del auto

mientras contaba los carteles de la ruta

al volver de las vacaciones.

Tenía cuatro años y todavía

no sabía escribir mi nombre.

Siempre fui buena para los números,

podía resolver ecuaciones

con variables que ya estaban dadas.

Cuando en el colegio me dijeron

escribí tu primera historia

dije números, dame números.

Mi tía murió y murieron las navidades,

la cena en el patio,

la casa en Flores, algo de la familia.

Ante la primera pérdida

agarré una hoja

y empecé a escribir. 
As referencias à infância trazem a ideia de uma ordem literalmente perdida (não nostálgica, não idealizada): "Cuando era chica me gustaba/ separar los caramelos por colores/ antes de comerlos" (KASZTELAN, 2013, p. 37). Os números e a economia das imagens, dos cartazes, dos outdoors que aparecem ao longo da estrada são prévios ao ingresso na escrita do nome, ou seja, ao ingresso na identificação nominal e na cidadania. A escrita de poesia é, ao mesmo tempo, reação perante a perda - tentativa de compensação - e uma nova experiência de perda: perder os números, perder o desejo dos números, perder a potência; porém é a partir da presença dessa perda que tem lugar a única possibilidade de trabalhá-la. Assim, a economia parece pertencer, nestes poemas, ao âmbito da potência da infância, seguindo o pensamento de Agamben em Infância e história e o de Roman Jakobson em "Dos aspectos da linguagem e dois tipos de afasia". Mas também, a poesia - esse recurso a uma linguagem não cidadã, não nominal, não identificatória - se dá como uma recuperação (falha) dessa in-fância e dos seus números. Economia e poesia poderiam ser pensadas como práticas infantis, como práticas de montagem de restos, como pensa, por exemplo, Benjamin, já que em lugar de evitar o vazio da significação, fazem dele o motor da brincadeira e do poema: "No huir del vacío, habitarlo" (KASZTELAN, 2013, p. 43).

Perda e aquisição são, então, noções evidentemente relacionais, e como tais, de contato. O mote recorrente na primeira parte do livro sobre o qual se tecem as medições e tentativas de estabelecer relações lógicas é, como vimos no primeiro poema, o da respiração. Elemento de troca entre o dentro e o fora, aquele elemento que negociamos (junto com as vibrações que nele se veiculam, os sons) com os outros. Respirar é sempre uma equação, e uma tensão: "No aprendí a respirar/ de la manera correcta;/ me queda el gesto/ de acapararlo todo/ em uma sola bocanada" (2013, p. 12). O gesto de tomar ar, a "bocanada" que inicia as frases, a boca cheia de nada, que se mantém no espírito do grego. Como diz Daniel Heller Roazen (2005), a letra $h$, que dera origem ao espíritu, do grego, é justamente o resto daquele vínculo entre deuses e humanos, entre a não linguagem e a linguagem, entre o silêncio e a fala, ainda marcado na linguagem. Tomar ar, inspirar(-se), se entusiasmar, aspirar as musas, ou o deus: "No conocí/ la forma del limite" (KASZTELAN, 2013, p. 12). Evidentemente, e isto desde o diálogo Ion de Platão, a inspiração, entusiasmo ou possessão, caracteriza a atividade poética, porém se dá sempre como uma negociação: daqui que nos hinos gregos (mas também nos indianos) o poeta sempre negocie a inspiração com os deuses, propondo trocas:

\section{Hino Homérico a Afrodite (nro. 10)}

Cantarei Citéria nascida em Chipre, a qual dá aos mortais presentes melífluos; em seu rosto adorável ela está sempre rindo, e uma flor adorável sempre corre sobre ele. Salve, deusa, rainha da bem-cultivada Salámis e de Chipre rodeado pelo mar: concede-me um canto adorável. E me lembrarei tanto de ti quanto de outro canto (HOMERO apud. MACEDO, 2007, p. 254).

Os poemas de Nurit Kasztelan, quase como a retórica de Spinoza, estão sempre medindo, contando, calculando, estabelecendo relações lógicas. Poderíamos dizer que, tematicamente, há um foco no racional, no cognitivo; e também performaticamente, já que a vontade de calcular, de administrar, é sistematicamente encenada. Mas se a 
economia da casa (ou seja, do poema e da livraria) não deixa de apontar para a "distribuição ordenada das coisas do mundo" (AGAMBEN, 2011, p. 45), a poesia parece se encarregar aqui de convocar essa partilha e mostrar que ela não, não funciona totalmente, ela não fornece uma chave organizadora (do sentido) ou um princípio construtivo, mas que também não é facilmente dispensável porque há uma coreografia se montando em cada poema e cada livraria.

\section{REFERÊNCIAS}

AGAMBEN, Giorgio. O reino e a glória. Uma genealogia teológica da economia e do governo. Homo Sacer, II, 2. Tradução de Selvino Assmann. São Paulo: Boitempo, 2011.

BATAILLE, Georges. A parte maldita. Precedida de "A noção de despesa" Tradução de Júlio Castañón Guimarães. Rio de Janeiro: Imago, 1975.

CAILLOIS, Roger. Los juegos y los hombres. La máscara y el vértigo. Tradução de Jorge Ferrero. México: Fondo de Cultura Económica, 1986.

CHAUI, Marilena. "Alegria do pensamento e liberdade" (entrevista), Revista do Instituto Humanitas, UNISINOS, 397, XII, 06 de agosto de 2012. Disponível em:

www.ihuonline.unisinos.br/index.php?option $=$ com_content\&view $=$ article\&id $=4534 \&$ secao $=397$

DELEUZE, Gilles. SPINOZA. Le Cour de Gilles Deleuze. Cours Vincennes. 24/01/1978. Disponível em: www. webdeleuze.com/php/texte.php?cle $=194 \&$ groupe $=$ Spinoza\&langue $=5$

2002

. Espinosa. Filosofia prática Tradução de Daniel Lins e Fabien Pascal Lins. São Paulo: Escuta,

.Primera serie de paradojas. Del puro devenir", in: Lógica del sentido. Tradução de Miguel

Morey. Buenos Aires: Paidós, 2008.

DERRIDA, Jacques. "Envios", O cartão postal [1980]. Tradução de Simone Perelson e Ana Valéria Lessa. Rio de Janeiro: Civilização Brasileira, 2007.

. "Envío" Discurso inaugural do XVIII Congresso da Sociedade francesa de filosofia sobre o tema "a representação". In. DERRIDA, Jaques. La desconstrucción en las fronteras de la filosofía. Tradução de Patricio Peñalver. Barcelona: Paidós, 1996.

ESPÓSITO, Roberto. Communitas. Origen y destino de la comunidad. Buenos Aires: Amorrortu, 2007. GREGG, Melisa; SEIGWORTH (ed). Affect theory reader. Durham \& London: Duke University Press, 2010.

HELLER-ROAZEN, Daniel. Ecolalias. Sobre el olvido de las lenguas Tradução de Julia Benseñor. Buenos Aires: Katz, 2008.

JAKOBSON, Roman. Lingüística e comunicação. Tradução de Izidoro Blikstein e José Paulo Paes. São Paulo: Cultrix, 1971.

KASZTELAN, Nurit. Lógica de los accidentes. Bahía Blanca: Ediciones VOX, 2013.

MACEDO, José Marco Mariani de. A palavra ofertada. Uma análise retórica e formal dos hinos gregos e da tradição hínica grega e indiana. Tese (Doutorado em Letras Clássicas e Vernáculas). Faculdade de Filosofia, Letras e Ciências Humanas da Universidade de São Paulo, 2007.

MAUSS, Marcel. Ensaio sobre a dádiva. Tradução de Paulo Neves. São Paulo: Cosac Naify, 2013.

MITRAPOULOS, Angela. Contract \& contagion. From biopolitics to oikonomia, Wivenhoe. New York/Port Watson: Minor Composition, 2012.

PERROUX, François. Economía y sociedad. Coacción, Cambio, Don. Tradução de X. Cornudella. Caracas/Barcelona: Ariel, 1962.

SPINOZA, Baruch. Ética. Tradução de Lívio Xavier, Rio de Janeiro: Edições de Ouro, 1965. 
Recebido em 11/09/2015. Aprovado em 02/11/2015.

Title: Siempre fui buena para los números: poetry, affect and economy to Nurit Kasztelan Abstract: Over the past decades, art criticism often focused its reading efforts on relational aspect of contemporary productions. This interest was identified as a symptom of the "affective turn". It happened also in a significant part of poetry production that insists in a will to get out of oneself, in an intention to address: to go to the encounter with the Other, being the reader, being other languages, an encounter that implicates a power to affect and be affected. My work proposes to discuss about affects in an economy, i.e., oikonomia. For that, I will analyze some poems from the book Lógica de los Accidentes, by Nurit Kasztelan (Editorial VOX, 2013) and how the barter economy and its fails are inseparable from an affective logic.

Keywords: Contemporary poetry. Affect. Economy. 